\title{
SENSORIAMENTO REMOTO APLICADO NO USO E OCUPAÇÃO DO SOLO DA BACIA HIDROGRÁFICA DO RIO SALGADO-BA
}

Lídia Raíza Sousa Lima Chaves Trindade - lidiaraiza@hotmail.com

Universidade Estadual do Sudoeste da Bahia

Pedro Augusto Ferraz e Silva - pedroaugsto@ outlook.com

Universidade Estadual do Sudoeste da Bahia

Romário Oliveira de Santana - engenheiro.romario@ hotmail.com

Universidade Estadual do Sudoeste da Bahia

Natália Andrade Silvão - naty_andrade18@ hotmail.com

Universidade Estadual do Sudoeste da Bahia

Alison Silva dos Santos - alisonss@ outlook.com

Universidade Estadual do Sudoeste da Bahia

Najla Evangelista Sales - najla.sales@ outlook.com

Universidade Estadual do Sudoeste da Bahia

Mariana Carneiro Viana - marianacviana@ outlook.com

Universidade Estadual do Sudoeste da Bahia 


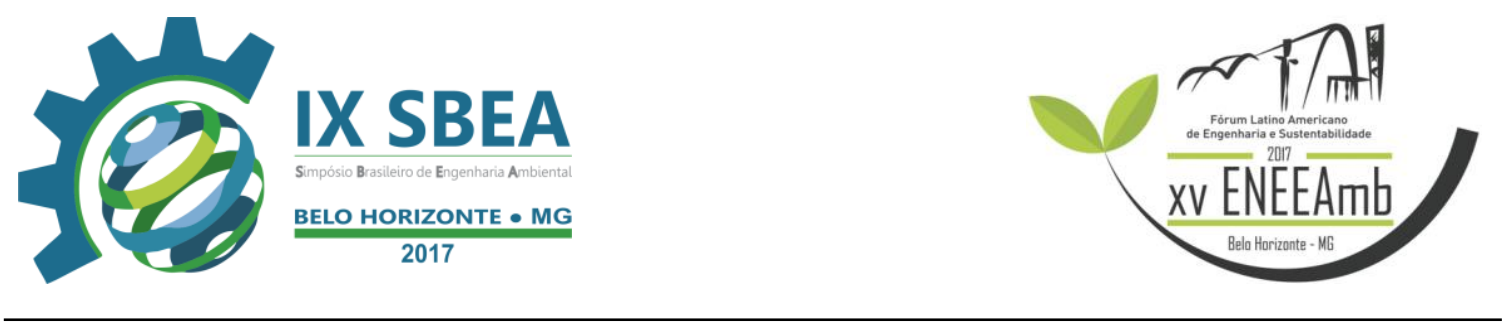

\section{RESUMO}

Objetivou-se com o presente estudo o mapeamento do uso e cobertura vegetal do solo da bacia hidrográfica do Rio Salgado-BA, de forma a subsidiar o planejamento de seus recursos naturais, por meio da utilização de técnicas de sensoriamento remoto e Sistema de Informação Geográfica (SIG). Foram utilizadas imagens de 30 metros de resolução espacial, com 7 bandas espectrais do sistema sensor TM abordo do satélite Landsat 5, que foram importadas e georreferenciadas por meio de pontos de controles passíveis de identificação na carta topográfica e na imagem. Após esse processo as imagens foram recortadas utilizando o limite geográfico da bacia hidrográfica gerada e classificadas com o objetivo de separar as áreas. Os resultados das classes de uso e cobertura do solo foram Pastagens 600,47 km² (57,65\%), Floresta 301,40 km² (28,94\%), Solo exposto $139,25 \mathrm{~km}^{2}(13,37 \%)$ e Cursos d'água $0,35 \mathrm{~km}^{2}(0,034 \%)$. A aplicação do Sensoriamento Remoto demonstrou ser uma ferramenta importante para a análise da dinâmica e caracterização espacial da bacia em questão.

Palavras-chave: geotecnologias, recursos naturais, sistemas de informação geográfica.

\section{INTRODUÇÃO/OBJETIVO}

A ação antrópica desordenada no meio ambiente causa um intenso desgaste e destruição dos sistemas naturais e como consequência provoca a desertificação, a contaminação dos recursos hídricos, o esgotamento dos recursos do solo, a diminuição da diversidade ecológica, entre outros problemas de degradação (COMISSÃO MUNDIAL SOBRE MEIO AMBIENTE E DESENVOLVIMENTO, 1991).

A análise do uso e cobertura da terra contribui para a compreensão das paisagens em escala local até escala global e permite avaliar as mudanças ocorridas e a substituição da cobertura natural pelas atividades antrópicas (MIRANDA et al., apud CRISCUOLO et al., 2004). Paisagem pode ser definida como um conjunto de formas que num dado momento, exprime as heranças capazes de representar as sucessivas relações entre o homem e a natureza, produzidas através do tempo (SANTOS, apud CRISCUOLO et al., 2004).

A expressão "uso da terra" pode ser entendida como a forma pela qual o espaço está sendo ocupado pelo homem (ROSA, 1992), sendo assim, é importante considerar a 


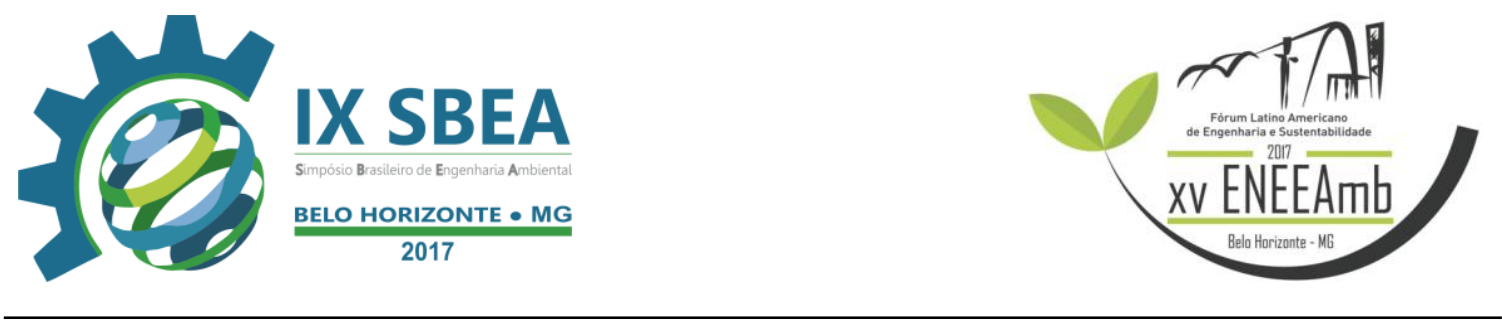

forma que este espaço está sendo ocupado, ou seja, se é explorado de forma organizada e produtiva, conforme cada região.

O conhecimento dos padrões de uso e cobertura da terra de uma região é de fundamental importância para apontar a tipologia de manejo aplicado e identificar problemas ambientais que se configuram em decorrência do uso. Portanto, para se estudar o uso da terra é necessário obter informações sobre o modo como o espaço está sendo alterado pelo homem e como se caracteriza a cobertura vegetal original (VIECILI et al., 2005).

Para análise espacial e armazenamento dos dados provenientes de diferentes fontes foram desenvolvidos os sistemas de informação geográfica (SIGs). Esses sistemas permitem a inclusão, exclusão, substituição e cruzamento de várias informações espaciais/temporais, bem como gerar um banco de dados codificados espacialmente, promover ajustes e cruzamentos simultâneos de grande número de informações (ASSAD et al., 1998; BRETERNITZ, 2006).

Diante o exposto, o presente estudo teve como objetivo classificar imagens do satélite Landsat - 5 para elaboração do mapa de uso e cobertura do solo da bacia hidrográfica do Rio Salgado, localizado no sul da Bahia.

\section{METODOLOGIA}

A área de estudo está localizada na bacia hidrográfica do Rio Salgado, na região no sul da Bahia à $14053^{\prime} 59^{\prime \prime} \mathrm{S}$ e 390 26'46” W, com uma área de 1041,45 km². A bacia abrange os municípios de Firmino Alves, Santa Cruz da Vitória, Floresta Azul, Ibicaraí e Itapé, sendo parte integrante da bacia do Rio Cachoeira.

Foram utilizadas as imagens de 30 metros de resolução espacial com 7 bandas espectrais do sistema sensor TM abordo do satélite Landsat 5, fornecidas pelo Diretório Geral de Imagens - DGI do INPE. Diante da disponibilidade de inúmeras imagens de diferentes datas, para a posterior escolha da imagem foi levado em consideração a menor cobertura de nuvens possível, neste sentido, a cena selecionada foi referente ao dia 29 de junho de 2013. Para o pré-processamento e o próprio processamento das imagens foi utilizado o software ArcGis 10/ArcMap do ESRI. 


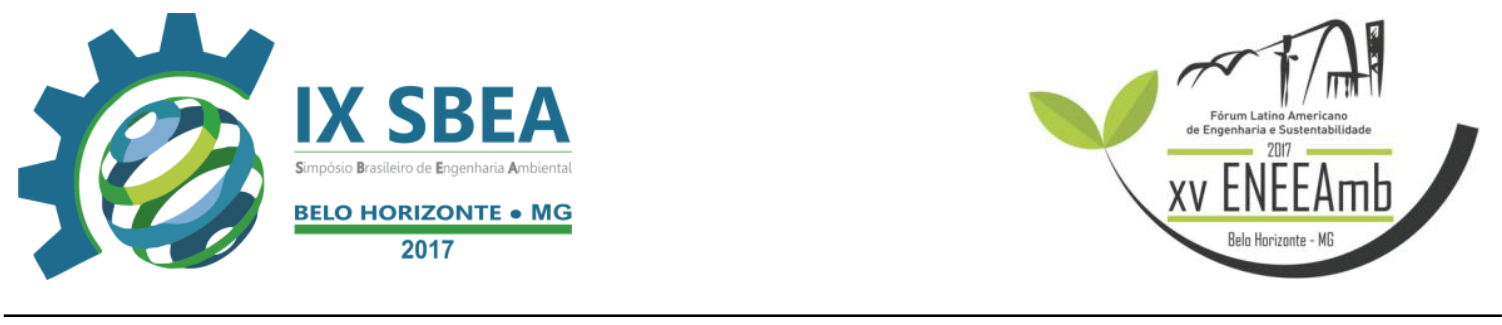

O pré-processamento utilizado nesta metodologia consiste em correções geométricas, tais como adequar o sistema de projeção e refinar o georeferenciamento das bandas. Para a posterior classificação e outros processamentos da imagem foi necessário juntar as bandas, disponibilizadas em raster, em uma composição de bandas RGB. A composição escolhida foi a RGB 321, que apresenta cores verdadeiras, aproximando-se da imagem real.

Com a composição já criada, segue a classificação supervisionada da bacia, a qual consiste em desenhar polígonos de amostras para classes temáticas, neste caso: Floresta, Pastagem, Solo exposto e Cursos D'agua, sendo que cada classe teve uma média de 10 amostras de no mínimo 70 pixels. Após coletar as amostrar referente a cada classe temática, foi feita uma análise de homogeneidade das amostras, criando um arquivo de assinatura digital espectral. Para a classificação da imagem, utilizou-se a ferramenta "Maximum likelihood Classification", que apresenta como vantagem um tipo de classificação mais precisa, criando um arquivo de saída permanente.

Para a geração do mapa de uso e cobertura vegetal da bacia, foi realizado um refinamento na classificação supervisionada a fim de remover ruídos e regiões isoladas, resultando em um aspecto visual melhor. Para tal refinamento realizou-se um realce de filtragem, que elimina ruídos da imagem decorrentes de erros ocorridos durante a classificação. Após o processo de filtragem, realizou-se uma suavização e limpeza de bordas, o que reduz os ruídos que restaram, seguido da remoção de grupos isolados e eliminação de regiões pequenas. Por fim, foi realizada a extração de dados apenas da bacia hidrográfica do Rio Salgado, computando a área de cada feição.

\section{RESULTADOS E DISCUSSÃO}

Com a classificação das imagens multiespectrais obtidas (Figura 1) foi possível mapear diferentes tipos de uso e cobertura do solo, bem como o percentual da área de ocupação dentro da bacia conforme apresentado na Tabela 1. 


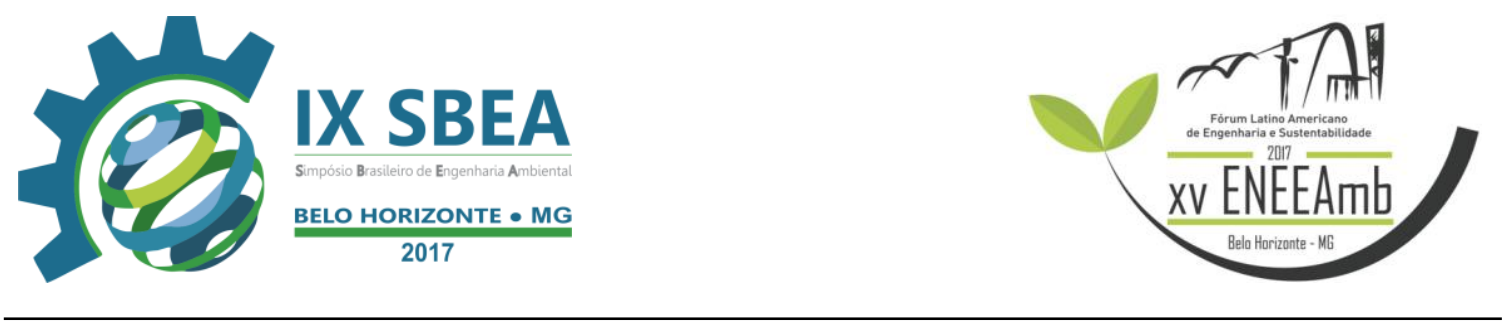

Tabela 1 - Quantificação do uso e ocupação do solo na bacia hidrográfica do Rio Salgado-BA, em junho de 2013.

\begin{tabular}{ccc}
\hline Classes & Área $\left(\mathrm{Km}^{2}\right)$ & $\%$ \\
\hline Floresta & 301,40 & 28,94 \\
Pastagem & 600,47 & 57,65 \\
Solo Exposto & 139,25 & 13,37 \\
Cursos d'água & 0,35 & 0,034 \\
\hline Total & 1041,45 & 100 \\
\hline
\end{tabular}

Com as análises dos dados obtidos a partir da classificação verificou-se que a bacia hidrográfica do Rio Salgado apresenta uma área total de $1041,45 \mathrm{~km}^{2}$, desta área a classe Pastagem representa grande parte, ocupando cerca de 57,65\%, equivalente a $600,47 \mathrm{~km}^{2}$ da área total da bacia, o que demonstra alto grau de antropização, com elevado índice de desmatamento, muito comum na região, buscando atender as atividades agropecuárias, sobretudo a criação extensiva de gado. Christofolletti (1980) argumenta que há um rompimento do equilíbrio natural do ecossistema quando os meios físicos se modificam, ou seja, para a área da bacia de estudo, a grande abrangência da área de pastagem pode vir a reduzir com o tempo as áreas de vegetação natural. O uso intensivo de áreas com pastagem e a fragmentação ocasionada por esta atividade, gera impactos de forma negativa sobre a biodiversidade, podendo em muitos casos, levar a extinção de determinadas espécies no local (FERREIRA, 2005).

Floresta foi a segunda classe mais representativa entre os diferentes tipos de uso, com 28,94\% (301,40 km²), indicando que a bacia não está em um bom estado de conservação. Do ponto de vista ecológico, a intensa redução da cobertura florestal regional traz implicações sobre a composição e distribuição de espécies vegetais e animais, processo que geralmente ocasiona a diminuição do fluxo gênico entre as populações, aumentando assim as chances de extinção local (PRIMACK \& RODRIGUES, 2001). Segundo Benatti et al., (2015), a cobertura florestal é essencial no 


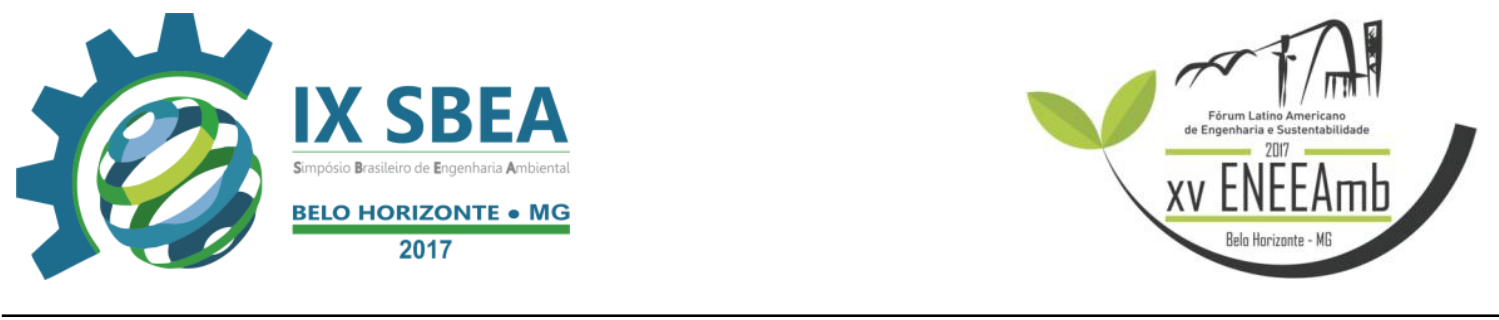

ecossistema, pois confere proteção ao solo contra o impacto direto das gotas de chuva, reduzindo a velocidade de escoamento superficial e, por conseguinte, favorecendo a capacidade de infiltração da água no solo.

A classe de Solo exposto, que são áreas com um grau mais elevado de degradação somam aproximadamente $139,25 \mathrm{~km}^{2}$, que equivale a $13,37 \mathrm{~km}^{2}$ da área da bacia. Segundo Lopes et al. (2005) a maior exposição do solo favorece a incidência de processos erosivos, que carregam o material particulado para os cursos d'água, comprometendo sua qualidade devido ao aumento da turbidez e consequentemente desencadeando em processos de assoreamento do leito.

A área de menor predominância foi a classe de cursos d'água, ocupando 0,037\% $\left(0,15 \mathrm{~km}^{2}\right)$ da bacia hidrográfica. Pinheiro et al., (2011) argumentam que a alocação de estradas em divisores de água favorece a atenuação dos processos de escoamento superficial, erosão e, por consequência, de assoreamentos de cursos d'água.

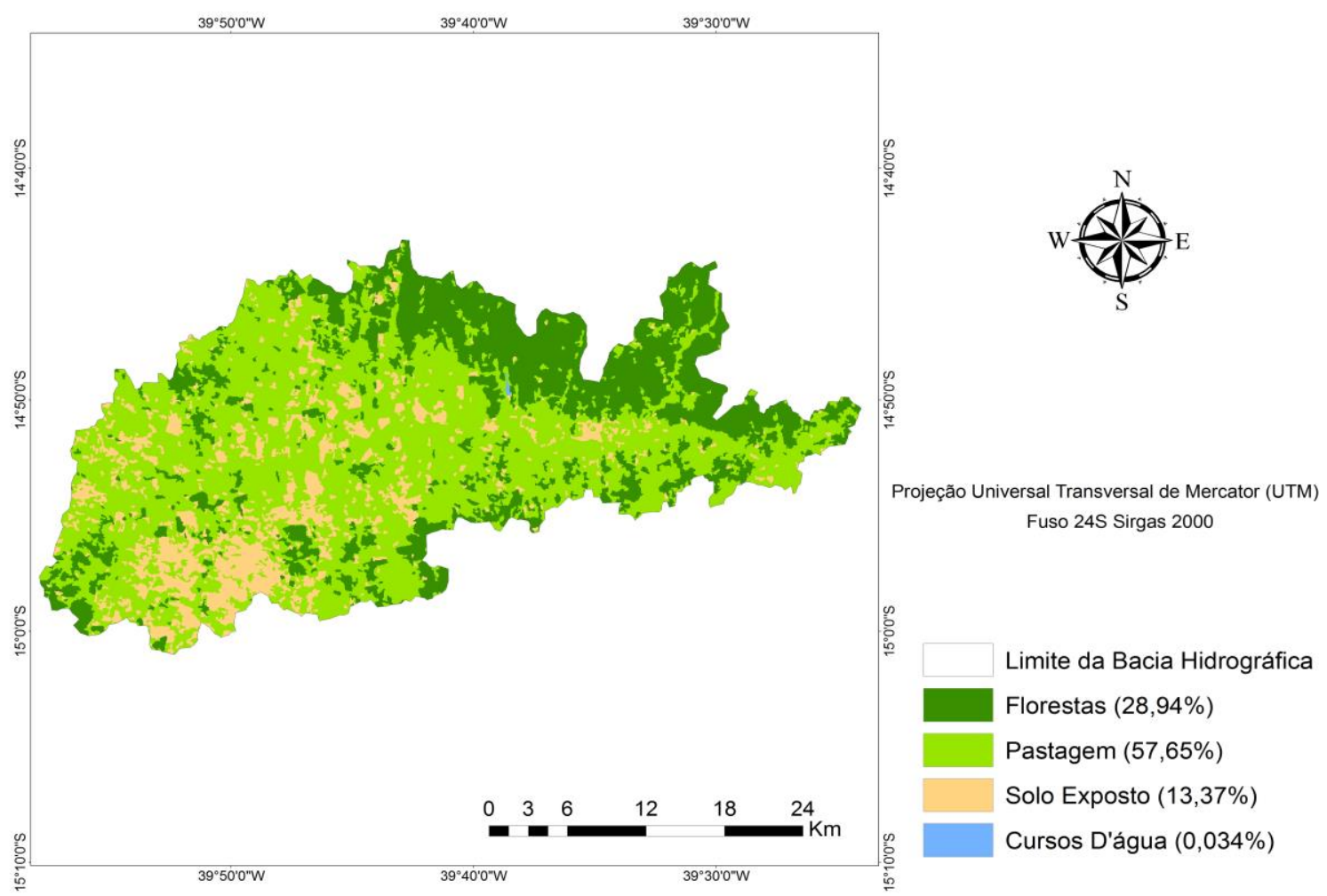

Figura 1 - Distribuição das classes de uso e cobertura do solo na bacia hidrográfica do rio Salgado-BA. 


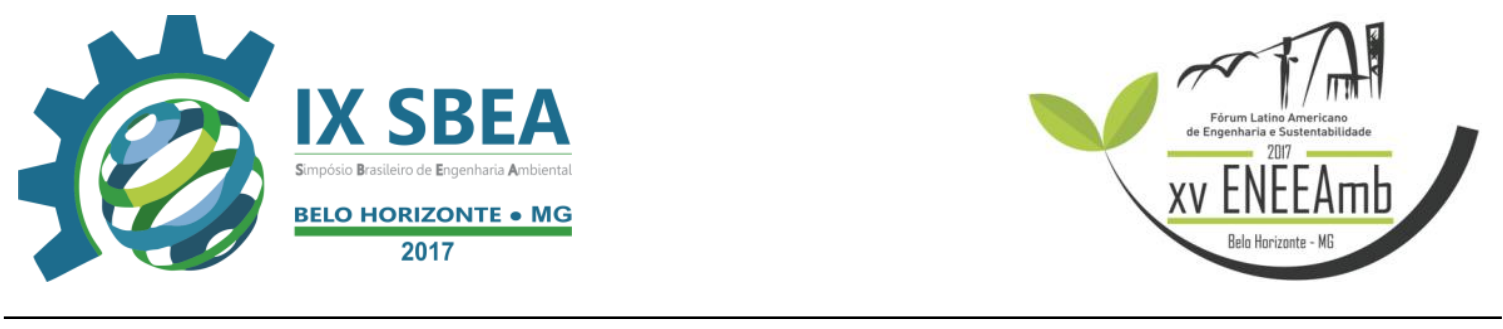

\section{CONCLUSÕES/RECOMENDAÇÕES}

A aplicação do Sensoriamento Remoto para o estudo da bacia hidrográfica do Rio Salgado-BA demonstrou ser uma ferramenta importante para a análise da dinâmica e caracterização espacial e com base nas análises, pode-se concluir que a Pastagem foi a classe mais representativa entre os diferentes tipos de uso, com 57,65\% (600,47 km²) da área da bacia, nota-se que a mesma se encontra em estado de degradação de seus recursos naturais.

A classe floresta foi a segunda predominante, ocupando $28,94 \%\left(301,40 \mathrm{~km}^{2}\right)$, seguida do Solo exposto que corresponde a $13,37 \%\left(139,25 \mathrm{~km}^{2}\right)$ da área, a classe de menor predominância foi a de cursos d'água, que ocupou $0,034 \%\left(0,35 \mathrm{~km}^{2}\right)$ da bacia hidrográfica.

\section{REFERÊNCIAS BIBLIOGRÁFICAS}

ASSAD, M. L. L; HAMADA, E; CAVALIERI, A. Sistema de informações geográficas na avaliação de terras para agricultura. In: ASSAD, E. D.; SANO, E. Sistemas de informações geográficas: aplicações na agricultura. 2.ed. Brasília, DF: EMBRAPA-SPI/EMBRAPA-CPAC, 1998. p.191-229.

BENATTI, D. P.; TONELLO, K. C.; LEITE, E. C.; FARIA, L. C.. Morfometria e uso e cobertura de uma microbacia no município de Sete Barras, São Paulo. Irriga (UNESP Botucatu), v. 21, p. 21-32. 2015.

BRETERNITZ, V. J. Sistemas de informações geográficas: uma visão para administradores e profissionais de tecnologia da informação. Disponível em: <http://br.monografias.com/trabalhos/sisin/sisin.shtml>. Acesso em: 10 de fevereiro de 2017.

CHRISTOFOLETTI, A. Geomorfologia. São Paulo: Edgard Blücher, 1980. 
COMISSÃO MUNDIAL SOBRE MEIO AMBIENTE E DESENVOLVIMENTO.

Nosso Futuro Comum. 2. Ed. Rio de Janeiro: Fundação Getúlio Vargas, 430 p., 1991.

FERREIRA, A. B. et al. Análise comparativa do uso e ocupação do solo na área de influência da Usina Hidrelétrica Capim Branco I a partir de técnicas de geoprocessamento. SIMPÓSIO BRASILEIRO DE SENSORIAMENTO REMOTO, 12., 2005, Goiânia. Anais... São José dos Campos: INPE, 2005. p. 2997-3004.

LOPES, V.C.; LIBÂNIO, M. Proposição de um índice de estações de tratamento de água (IQETA). Engenharia Sanitária e Ambiental. Rio De janeiro. Vol.10- $\mathrm{n}^{\mathrm{o}}$ 4out/dez 2005, 318-328.

MIRANDA, E. E. de; DORADO, A. J.; GUIMARÃES, M.; MANGABEIRA, J. A.; MIRANDA J. R. Impacto ambiental y sustentabilidad agrícola: La contribución de los sistemas de informaciones geográficas. In: CRISCUOLO, C.; GUIMARÃES, M.; MIRANDA, E. E. de. Uso e cobertura das terras na Região dos Rios Pardo e MogiGuaçú, Estado de São Paulo. Campinas: Embrapa Monitoramento por Satélite, 42p., 2004.

PINHEIRO, R. C., TONELlO, K.C.; VALENTE, R.O.A.; MINGOTI, R.; SANTOS, I.P. Ocupação e caracterização hidrológica da microbacia do Córrego Ipaneminha, Sorocaba-SP. Irriga, Botucatu, v. 16, n. 3, p. 234-245, 2011.

PRIMACK, R. B.; RODRIGUES, E. Biologia da Conservação. Londrina: Ed. Planta, 328p., 2001.

ROSA, R. Introdução ao Sensoriamento Remoto. 2aed.rev. Uberlândia. Ed. da Universidade Federal de Uberlândia, 264p., 1992.

SANTOS, M. A natureza do espaço. Técnica e Tempo. Razão e emoção. In: CRISCUOLO, C.; GUIMARÃES, M.; MIRANDA, E. E. de. Uso e cobertura das terras 
na Região dos Rios Pardo e Mogi-Guaçú, Estado de São Paulo. Campinas: Embrapa Monitoramento por Satélite, 42p., 2004.

VIECILI F. L.; LAPOLLI E. M.; POMPÊO C. A. A carta de uso e cobertura das terras como subsídio à determinação do "fator c" da equação universal de perda de solos - Microbacia Hidrográfica do Rio Caeté. Alfredo Wagner, Santa Catarina, Brasil. Disponível em: Acesso em: 10 de fevereiro de 2017. 